\title{
Effect of rheology on mass transfer and bubble sizes in a bubble column operated in the heterogeneous regime
}

\author{
F.Augier, P.Maximiano Raimundo
}

IFP Energies nouvelles, Rond-point de l'échangeur de Solaize, BP 3, 69360 Solaize, France

\section{Abstract}

A recently developed measurement method has been applied for the first time to the characterization of a bubble column operated in the heterogeneous regime and in presence of nonNewtonian fluids. The resulting measurements of bubble size are completed with local gas holdup and global mass transfer characterizations. A strong impact of rheology on both bubble size and mass transfer is observed, at any tested superficial gas velocity. A dissociation of the liquid side mass transfer $\mathrm{k}_{\mathrm{L}}$ and the specific interfacial area $(\mathrm{a})$ is proposed. Results show that the $\mathrm{K}_{\mathrm{L}}$ model previously validated in stirred tanks filled with complex fluids is satisfyingly extended to bubble columns. The incoming databank will be of great help to develop and validate multiphase hydrodynamic models, especially in the scope of Biotechnology and associated systems of complex rheology.

\section{Keywords}

Characterization, multiphase reactor, bubble column, bubble size, mass transfer, non-Newtonian. 


\section{Introduction}

The use of bubble columns is attractive for many industries thanks to the simplicity of their geometries and their rather good performances in term of mixing and mass transfer. In biological industry, bubble columns are often used because of their ease of cleaning and sterilization. But the involvement of fermentation broths in bubble columns lead to potential issues. One of them is the complex rheology of some cultures, that may affect the hydrodynamics and the mass transfer. For this reason, the effect of rheology on mass transfer in bubble columns is a current research topic, and decades of studies have allowed to develop many correlations to assist industrial designs ${ }^{[1,2]}$. If the state of the art is clear concerning how to consider the effect of rheology on global mass transfer coefficient $\left(k_{L} \mathrm{a}\right)$, the underlying mechanisms are not that clear due to the difficulty to dissociate effect on the liquid side mass transfer $\left(\mathrm{k}_{\mathrm{L}}\right)$ from the one on the interfacial area (a). Difficulties are first due to the lack of measurement method able to measure accurately the interfacial area at moderate to high gas holdup, i.e. in hydrodynamic regimes of industrial interest. As a consequence, it is difficult to choose the most suitable $k_{L}$ model among the disparity of existing ones ${ }^{[1]}$.To overcome this issue, the multi-probe method has been used in bubble columns by several authors to measure bubble sizes in various conditions ${ }^{[3-7]}$. As pointed out by authors, the method is not adapted to fully heterogeneous regimes, because nearly vertical bubble trajectories are assumed to compute bubble velocities and chord lengths. Another limitation is the difficulty to estimate a Sauter mean diameter from mean bubble chord measurements, because the deconvolution is based on the bubble size distribution, that can hardly be computed without assumptions on its shape (lognormal or else). Consequently, the few available studies ${ }^{[3-7]}$ provide very useful results but reported profiles of radial bubble sizes are considered as qualitative.

In recent previous works, a measurement method has been developed to measure Sauter mean diameters in bubble columns ${ }^{[8]}$. This method, which is briefly presented in the following section, does not assume vertical trajectories of bubbles as it is based on a statistical analysis of the spatial cross 
correlations between the phase functions between of two neighboring optical probes. The mean size measurement is accurate in all the positions in the column and over a wide range of operating conditions. The uncertainty of the measurement is considered typically below $15-20 \%{ }^{[8]}$ and below $10 \%$ if no reverse gas-flow. It has been successfully validated in the heterogeneous regime and applied since to characterize the effect of scale-up on bubble sizes ${ }^{[9]}$, and the effect of additives ${ }^{[10]}$. Besides, the method has been used and validated in stirred reactors ${ }^{[11]}$ filled with water or shearthinning solutions of polymers (CMC and Xanthan Gum). As the CC Method has been found efficient in bubble columns under heterogeneous regime, and in stirred tanks with shear-thinning fluids, it is proposed in the present study to investigate its use on bubble columns involving shear-thinning fluids. The technique is used to investigate a bubble column filled with various fluids: water, $C M C$ and Xanthan Gum Solutions, in a wide range of superficial gas velocities $V_{s g}$ (from 0.03 to $0.3 \mathrm{~m} / \mathrm{s}$ ). Original bubble size radial profiles are measured with a sufficient confidence to consider their future use for CFD and Population Balance models validation, which is the primary motivation of the present study. Gemello et al. ${ }^{[12]}$ have shown that CFD coupled with population balance models was able to predict very accurately the bubble size radial distribution in bubble columns filled with water, and similar investigations are expected with non-Newtonian fluids.

Results are also coupled with additional measurements of gas holdup, and global mass transfer $\left(k_{\llcorner} a\right)$. Results are discussed and used to fit a simple set of correlations that may be useful for design purpose. A global estimation of the liquid side mass transfer $\left(k_{L}\right)$ is also proposed. The effect of rheology on $\mathrm{K}_{\mathrm{L}}$ is further discussed and compared with the model of $\mathrm{K}_{\mathrm{L}}$ recently validated in a stirred tank involving the same fluids. 


\section{Experimental Setup}

\section{Bubble column}

Gemello et al. ${ }^{[13]}$ have reported some CFD simulations of bubble columns and comparisons with experimental data of Raimundo et al ${ }^{[8]}$ at different scales. A good agreement was found between simulations and experiments for bubble columns of internal diameter equal or higher than $400 \mathrm{~mm}$. One possible explanation is that, at lower scale, hydrodynamics is more strongly affected by wall effects and CFD models require a specific care on the wall treatment that are not necessary above a given scale. For this reason, a column diameter $D$ of $400 \mathrm{~mm}$ has been chosen to study the effect of rheology, as it is considered to be sufficiently large to be representative of industrial scales. The global geometry of the experimental setup is schemed on figure 1 . An initial ratio $H_{L 0} / D=4$ is used to fill the column. A column height of $3.25 \mathrm{~m}$ is sufficient to avoid a liquid overflow at any tested gas flow rate. The bubbles are generated by a perforated flat plate with 92 holes of $2 \mathrm{~mm}$ distributed in a triangular pitch of $15 \mathrm{~mm}$. Details are given in [9]. The choice of the gas sparger is critical for the development of the flow in the column. It has been found in a previous work with water ${ }^{[10]}$ that the chosen perforate plate induces a fast flow development as it generates bubble sizes that are close to their stable size all along the column. 


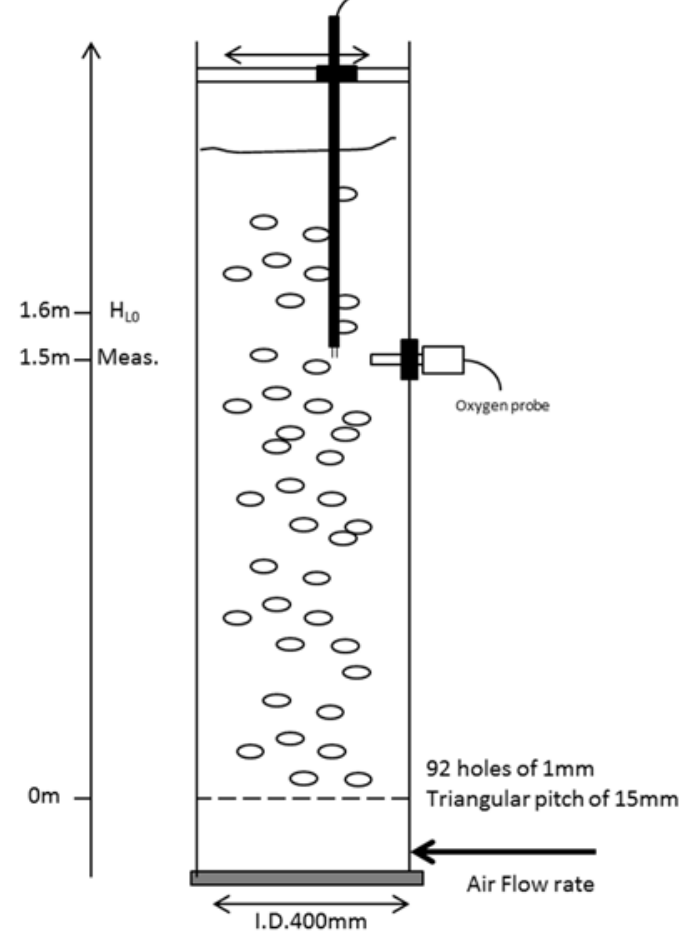

Figure 1: Experimental setup.

\section{Bubble size measurement}

The CC measurement method has been detailed in previous articles ${ }^{[8,9,11]}$ and is succinctly reminded here. The method relies on the recording of instantaneous phase functions at the tip of two neighboring optical probes ( $=1$ if gas is present at the tip of the probe, $=0$ if not). The device is built and commercialized by A2 Photonic Sensor in Grenoble, France. The two probes are located at the same horizontal level within a distance of $d=730 \mu \mathrm{m}$. The diameter of each probe is $125 \mu \mathrm{m}$. At each instantaneous sampling time, the Boolean signals generated by the two probes are multiplied. The resulting summation is divided by the summation of the individual signals from one probe. The resulting term is called spatial correlation coefficient $R_{g}(d)$ comprised between 0 and $1 . R_{g}(d)=1$ would signify that both probes record exactly the same phase function, and thus would signify that $d$ is so small compared to the bubbles size that each bubble in contact with one probe would also be in contact with the other probe, at the exactly same time. At the opposite, theoretically $R_{g}(d)=0$ would say that both recorded signals are completely uncorrelated, thus when a bubble is present at the tip 
of one probe, it is never present at the same time at the tip of the other probe. This situation is possible only if the distance between probes is higher than the bubbles size. Practically in bubbly flows $R_{g}(d)$ tends to the local gas holdup when $d$ increases, because both probes can be in contact with two different bubbles at the same time. It has been stated by a theoretical approach that $R_{g}(d)$ is related to the ratio between $d$ and $d_{32}$ the Sauter mean diameter of the bubbles present in the flow (see eq.1). The lower the $d / d_{32}$ the higher the correlation $R_{g}(d)$. It has also been found that the eccentricity of bubbles impact $R_{g}(d)$ and has to be taken into account. In the present studied an eccentricity of bubbles (ecc) of 0.7 is assumed, as measured in water and polymer solutions ${ }^{[8,11]}$, but more complex evolutions of eccentricity with physical properties may be investigated ${ }^{[14]}$. A minimum of 5000 bubbles are measured for each $d_{32}$ measurement to minimize statistical bias error. Therefore, the averaging time is function of gas hold-up and it can vary from $5 \mathrm{~min}$ up to $30 \mathrm{~min}$, in the case of the lower Vsg.

$d_{32}=\operatorname{ecc}^{1 / 3} \cdot \frac{1.5978}{1-R_{g}(d)}$

A limitation of the $\mathrm{CC}$ method stands in the distance between the two probes (d). Bubbles smaller than $d$ cannot be correctly detected. As a consequence, an important fraction of bubbles smaller than $d$ may increase the error of the measurements. In a previous work ${ }^{[11]}$, a comparison of Sauter mean diameter between the CC method and a photographic method has been performed in a stirred tank and with Water, CMC $0.25 \%$ wt and $0.5 \%$ wt solutions. Similar standard deviations $(<12 \%)$ were obtained between the three fluids, proving that small bubbles present in the flow does not affect significantly the $d_{32}$ measurement in the considered fluids. This could obviously be different in case of higher viscosity, as pointed out recently ${ }^{[12]}$ in a $\mathrm{CMC} 1 \%$ solution where tiny bubbles have been found as impacting strongly the gas-liquid mass transfer.

Measurements are done at the level of $1.5 \mathrm{~m}$ above the distributor $(H / D=3.75)$. According to different authors ${ }^{[9,15,16]}$ this ratio is high enough to neglect residual axial evolution. Radial profiles are 
measured on 5 radial positions, $r / R=0,0.2,0.4,0.6$ and 0.8 . Volume average bubble size is also measured. Experiments in water are measured at $r / R=0,0.25,0.5$ and 0.8 . The full development of the flow at $1.5 \mathrm{~m}$ above the distributor has been verified in a preliminary study. Comparisons of bubble sizes in Water and $\mathrm{CMC} 0.5 \%$ solution at $1 \mathrm{~m}$ and $1.5 \mathrm{~m}$ of height were found very similar, with less than $5 \%$ of relative differences of mean bubble sizes. Readers interested by the development of the flow on the lower part of the column may refer to the study of Gemello et al. ${ }^{[10]}$.

\section{Gas fraction measurement}

Local gas volume fraction (or gas holdup), $\varepsilon$, is measured with the first optical probe used to measure bubble size. The sample averaging on the phase function is used. The volume average on the column section is also measured.

\section{Mass transfer measurement}

The mass transfer coefficient $\left(k_{\llcorner} \mathrm{a}\right)$ in the column is estimated by using the measurement of the dissolved oxygen. Clark oxygen probes with fast response time (OX-100, Unisense, Denmark) are used to measure the dissolved oxygen in the liquid phase. The probe is located at $\mathrm{H}=1.5 \mathrm{~m}$ in the column. The response time of the probe is $0.6 \mathrm{~s}$, which is fast enough to neglect it in the kla calculation. The column is preliminary deoxygenated by injecting nitrogen gas in the column at the flow rate required for the following of the test. At a given time $t=0$, a 3 way valve is turned to switch from nitrogen to air injection at the same flow rate. The switch is almost instantaneous and does not impact hydrodynamics of the column. The oxygen probe records the dissolved oxygen until reach a plateau. The concentration curves were then processed by considering the liquid as if perfectly mixed and the gas phase as if moving in a plug flow reactor ${ }^{[17]}$. The mixing time has been measured in the column for different conditions (not reported). The mixing time is always measured above at least 3 times the transfer time $\left(1 / k_{\llcorner} a\right)$, confirming the assumption of fast mixing. Following Pinelli ${ }^{[18]}$ the uncertainty of the $\mathrm{k}_{\llcorner} \mathrm{a}$ measurement is approximately $20 \%$. 


\section{Fluid properties}

Following fluids are used: Tap water, as previously used ${ }^{[9]}$, Xanthan Gum (XG) solutions at $0.1 \% w t$ and $0.25 \% w t$, Carboxymethlycellulose (CMC) solutions at $0.25 \%$ wt and $0.5 \% w t$. The properties of the water used for experiments are reported in table 1.

Table 1 : Water properties

\begin{tabular}{c|c} 
Tap water analysis @ $\mathbf{2 0}{ }^{\circ} \mathbf{C}$. & \\
\hline Surface tension $(\mathrm{mN} / \mathrm{m})$ & 67 \\
Conductivity @ $25 \mathrm{C}(\mathrm{mS} / \mathrm{cm})$ & 559 \\
Carbonate $(\mathrm{mg} / \mathrm{L})$ & 0 \\
Hydrogenocarbonate $(\mathrm{mg} / \mathrm{L})$ & 251 \\
$\mathrm{pH}$ & 7.9
\end{tabular}

Regarding surface tensions of polymer solutions reported in literature ${ }^{[6,17]}$, and considering a linear effect of the polymer concentration, the surface tension in all considered fluids is estimated within the range of 67 to $74 \mathrm{mN} / \mathrm{m}$.

The Polymer solutions follow rheological behaviors close to Power law :

$\mu=K \cdot \dot{\gamma}^{n-1}$

where $\mathrm{K}$ and $\mathrm{n}$ are reported in table 2 . The viscosity of fluids is computed in Figure 2 over a wide range of shear rate. CMC0.5\% and XG0.25\% appears as the two most viscous fluids, and the order depends on the considered shear rate. Then $\mathrm{CMC} 0.25 \%$ is the $3^{\text {rd }}$ most viscous fluids excepted at very low shear rates. XG0.1\% is the lower viscous polymer solution, but still ten to hundreds of times more viscous than water. 
Table 2: Parameters of the Power law (Herschel-Bulkley) rheological model

\begin{tabular}{c|cc} 
& $\mathbf{K}$ & $\mathbf{n}$ \\
\hline Water & 0.001 & 1 \\
XG 0.1\% & 0.05 & 0.58 \\
XG 0.25\% & 0.7 & 0.38 \\
CMC 0.25\% & 0.05 & 0.82 \\
CMC 0.5\% & 0.44 & 0.65
\end{tabular}

Esmaeili et al. ${ }^{[6]}$ pointed out that the elastic behavior of fluids can also impact bubble sizes. Considering oscillatory rheological measurements, authors concludes that XG solutions have a nonnegligible elasticity, and that $\mathrm{CMC}$ rheology is governed by its viscous behavior. As a consequence authors proposed a correlation to predict bubble size, involving the elastic behavior of fluids. However, in the proposed model, the impact of elasticity stand rather low as it impacts bubble size with an average deviation of $10 \%$, while bubble sizes differs from a factor 2.5 between fluids. Moreover, the strongest viscoelastic effect was found for XG $0.5 \%$ solution, which is not involved in the present study. Despite the attention given to the study of Esmaeili[6], it has been preferred to not consider the difference of elasticity between fluids as its supposed effect is below the error of measurement methods used in the present study.

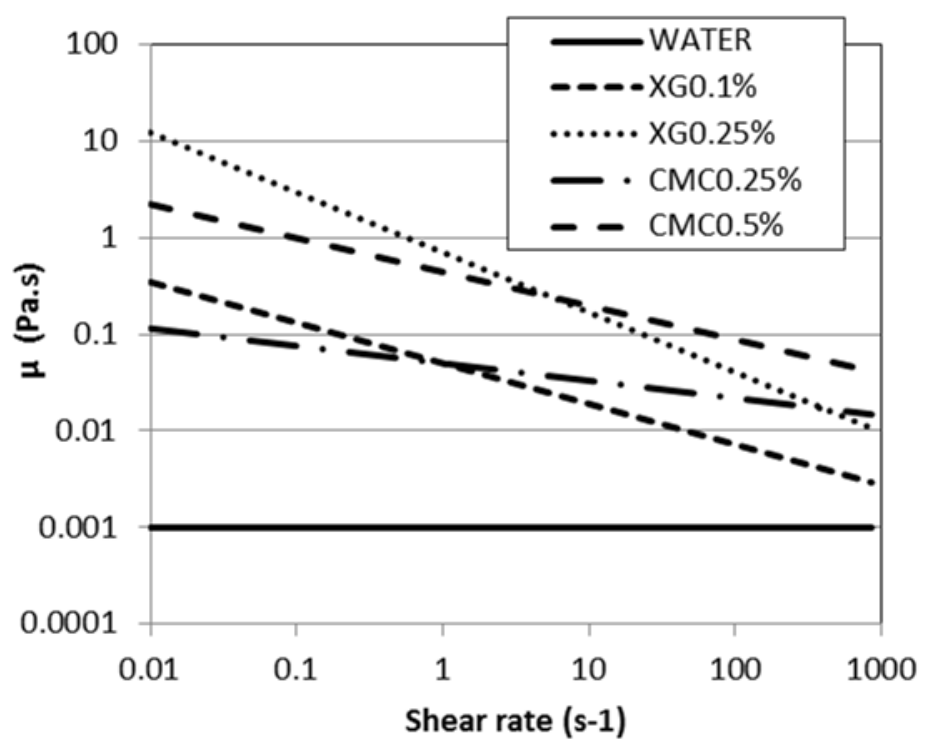

Figure 2: Viscosity of fluids at various shear rates. 


\section{Results and analysis}

Radial profiles of gas holdup and Sauter mean diameter are respectively reported in Figures 3 and Figure 4. Measurements are done at $\mathrm{V}_{\mathrm{sg}}=0.03,0.1,0.2$ and $0.3 \mathrm{~m} / \mathrm{s}$. At the lowest $\mathrm{Vsg}$, both holdup profiles and bubble size profiles are almost flat. Flat profiles are commonly associated to the homogeneous regime, with no or a few coalescence, no liquid recirculation. Compared to water, all the polymer solutions exhibits lower gas holdup. The lowest gas holdups are measured with, XG0.25\% coherent with its highest viscosity at low shear rate. Smallest bubbles are measured in water and biggest in XG0.25\%. Other fluids are roughly ranked according their viscosity at low shear rate. At higher $\mathrm{V}_{\mathrm{sg}}$ holdup and bubble size profiles follow parabolic trends as observed in literature ${ }^{[6]}$. These shapes are associated to the heterogeneous regime, governed by a large liquid recirculation and coalescence in the core region of the column. The order of holdup and bubble sizes between tested fluids stand almost unchanged when $\mathrm{V}_{\mathrm{sg}}$ increases. In particular bubble sizes in $\mathrm{XG0.25 \%}$ are always bigger than in $\mathrm{CMCO} .5 \%$. The compared fluids exhibit similar surface tensions, and their differences of viscoelasticity can only affect marginally bubble sizes. Moreover the same water is used in all the solutions. Consequently it is reasonable to consider that the apparent viscosity is the main parameter inducing differences of bubble sizes among tested fluids. Thus the apparent viscosity of $\mathrm{XG} 0.25 \%$ is supposed to be higher than $\mathrm{CMC} 0.5 \%$ one at any $\mathrm{V}_{\mathrm{sg}}$. Considering the viscosity of fluids reported in figure 2 , it suggests that the effective shear rate is always lower than approximately $5 s^{-1}$. But any evidence of strong deviation between some unconsidered properties may lead to different conclusions. 

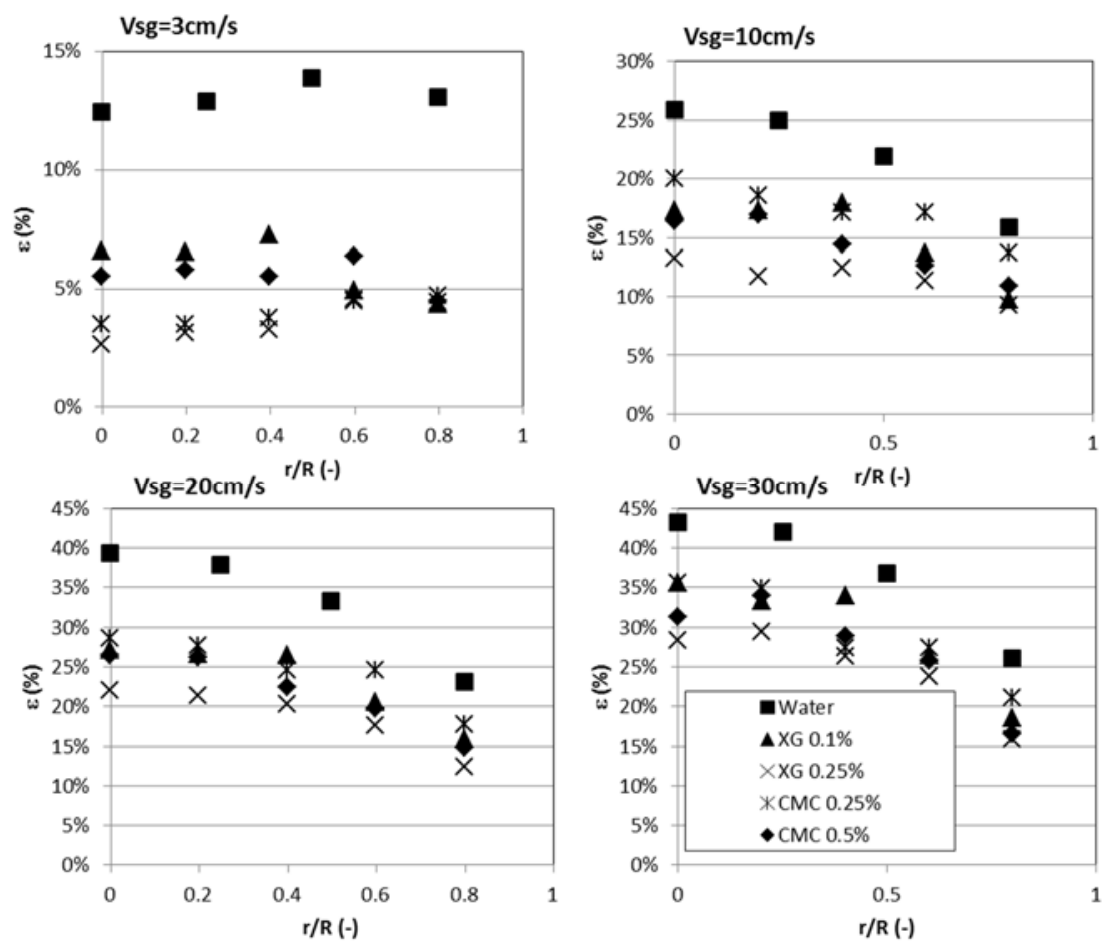

Figure 3 : Gas holdup radial profiles at $V_{s g}=3,10,20$ and $30 \mathrm{~cm} / \mathrm{s}$.
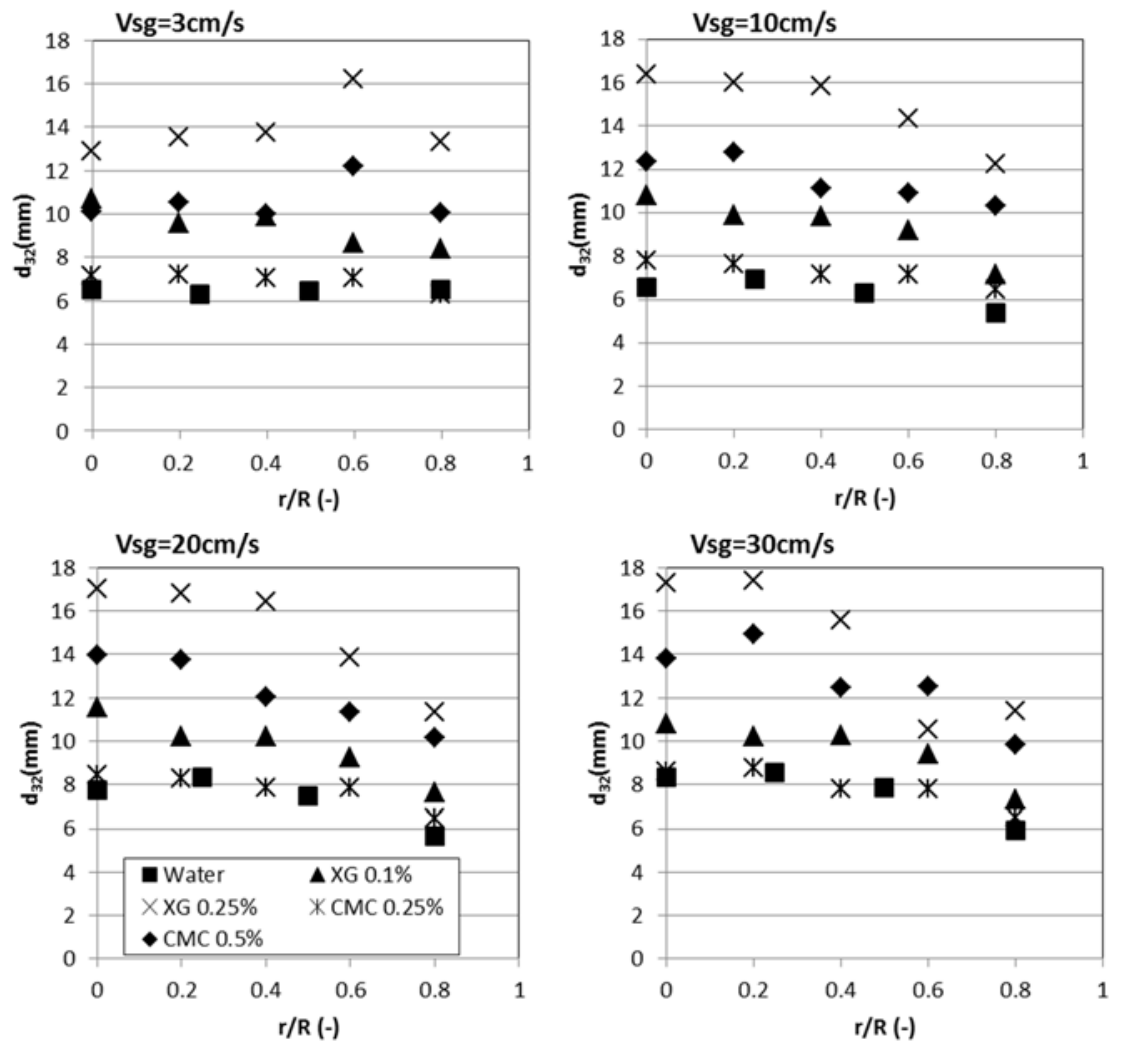

Figure $4: d_{32}$ radial profiles at $V_{s g}=3,10,20$ and $30 \mathrm{~cm} / \mathrm{s}$. 
In order to go further on the analysis of experimental results, radial profiles of gas holdup and bubble size are averaged over the section of the column, and results are presented in figure 5. Gas-liquid global mass transfer coefficients $\left(k_{\llcorner} a\right)$ are also reported in figure 5 . The figure points out some important results. First, $\mathrm{k}_{\mathrm{L}} \mathrm{a}$ in water is always much higher than any other fluids, and XG $0.25 \%$ fluid is the one exhibiting the lowest mass transfer. These results are coherent with gas holdup and bubble size measurements. Then, bubble size have almost a constant Sauter mean diameter for all gas velocities. The calculation of $k_{L} a, d_{32}$ and $\varepsilon$ allows to attempt to dissociate a from $k_{L}$, the latter being reported in figure 7 and discussed further.
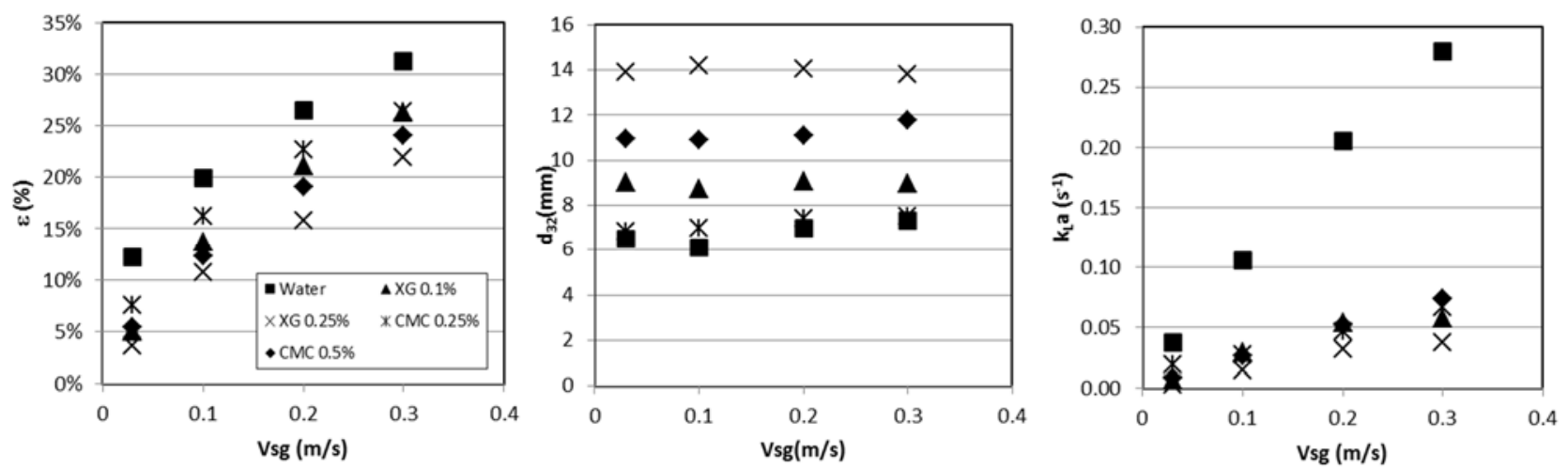

Figure 5 : mean Gas holdup, mean $d_{32}$ and kLa measurement versus $V_{s g}$.

The next step of the analysis consists to fit experiments with a simple correlation to quantify the effect of different parameters. Many different expressions exist in literature to predict mass transfer, gas holdup and bubble sizes ${ }^{[1,2,6]}$. Some authors attempt to develop correlations based on dimensionless groups, while others recommend very simple expressions involving dimensional variables. In the present study, the simple expression recommended by many authors ${ }^{[1]}$ is followed :

$X=a \cdot V_{s g}^{b} \cdot \mu^{c}$ 
With $\mathrm{X}$ being any of the following variable $d_{32}, \varepsilon, k_{\llcorner} a$ and $k_{L}$. It is well known however that other parameters potentially impact mass transfer, as the presence of surfactants or organic additives ${ }^{[10,19-}$ ${ }^{25]}$. But in the present study, efforts have been made to try to avoid all differences of properties between fluids excepted rheology. Unconsidered parameters are thus integrated in the constant (a) and are supposed unchanged between the tested fluids. The viscosity is classically calculated based on an effective shear rate proportional to the superficial gas velocity :

$\dot{\gamma}=A \cdot V_{s g}$

Where $A$ is a constant to fit. Schumpe and Deckwer ${ }^{[2]}$ suggests the value of $A=2800 \mathrm{~m}^{-1}$. Such a high value of $A$ may lead to shear rates in the range of $[80-800] \mathrm{s}^{-1}$ for the present work, and may lead to find $\mathrm{CMC} 0.5 \%$ as the most viscous fluid, exhibiting the lowest $\mathrm{k}_{\llcorner} \mathrm{a}$ and the biggest bubbles, contrary to observations. In table 3 , two set of parameters are fitted for each considered variable X. One consider the value of $A$ suggested by Schumpe and $\operatorname{Deckwer}^{[2]}\left(A=2800 \mathrm{~m}^{-1}\right)$; while the other is fitted to minimize the average error on $d_{32}$ modelling $\left(A=46 \mathrm{~m}^{-1}\right)$. A low value of $A$ is found to optimize the parameter fitting on $d_{32}$ results. This result is in agreement with previous observations on the ranking of fluids, as low shear rates classify XG0.25\% solution as the more viscous and high shear rate does not. But the value of $46 \mathrm{~m}^{-1}$ is low compared to the values found in literature. Moreover, the lowest value of $A$ also decreases the average error when applied to other variables such as $\varepsilon$ and $k_{\llcorner} a$, confirming the previous results. Parity diagrams of $d_{32}$, $\varepsilon$ and $k_{L} a$ are presented in figure 6 . As errors on the different correlations are relatively low, effects of gas velocity and liquid viscosity are pointed out as the major variables of the mass transfer and it is preferred to not include any additional effect in eq. 3. 
Table 3 : Results of the parameter fitting on eq.(3)

\begin{tabular}{|c|cccc|cccc|}
\hline & d32 & $\boldsymbol{\varepsilon}$ & $\mathbf{k L a}$ & $\mathbf{k L}$ & $\mathbf{d 3 2}$ & $\boldsymbol{\varepsilon}$ & $\mathbf{k L a}$ & $\mathbf{k L}$ \\
\hline \multirow{2}{*}{$\mathbf{A}$} & \multicolumn{7}{|c|}{$46 \mathrm{~m}^{-1}$} & \multicolumn{4}{c|}{$2800 \mathrm{~m}^{-1}$} \\
a & $1.36 \mathrm{E}-02$ & $3.56 \mathrm{E}-01$ & $5.82 \mathrm{E}-02$ & $1.71 \mathrm{E}-04$ & $1.70 \mathrm{E}-02$ & $4.22 \mathrm{E}-01$ & $4.76 \mathrm{E}-02$ & $1.01 \mathrm{E}-04$ \\
b & $3.69 \mathrm{E}-02$ & $5.71 \mathrm{E}-01$ & $7.60 \mathrm{E}-01$ & $0.00 \mathrm{E}+00$ & $4.60 \mathrm{E}-02$ & $6.51 \mathrm{E}-01$ & $9.83 \mathrm{E}-01$ & $0.00 \mathrm{E}+00$ \\
c & $9.02 \mathrm{E}-02$ & $-1.00 \mathrm{E}-01$ & $-3.00 \mathrm{E}-01$ & $-2.50 \mathrm{E}-01$ & $1.16 \mathrm{E}-01$ & $-7.00 \mathrm{E}-02$ & $-3.00 \mathrm{E}-01$ & $-2.50 \mathrm{E}-01$ \\
Error & $11.6 \%$ & $10.8 \%$ & $22.6 \%$ & $35.9 \%$ & $15.7 \%$ & $15.1 \%$ & $39.1 \%$ & $37.9 \%$ \\
\hline
\end{tabular}
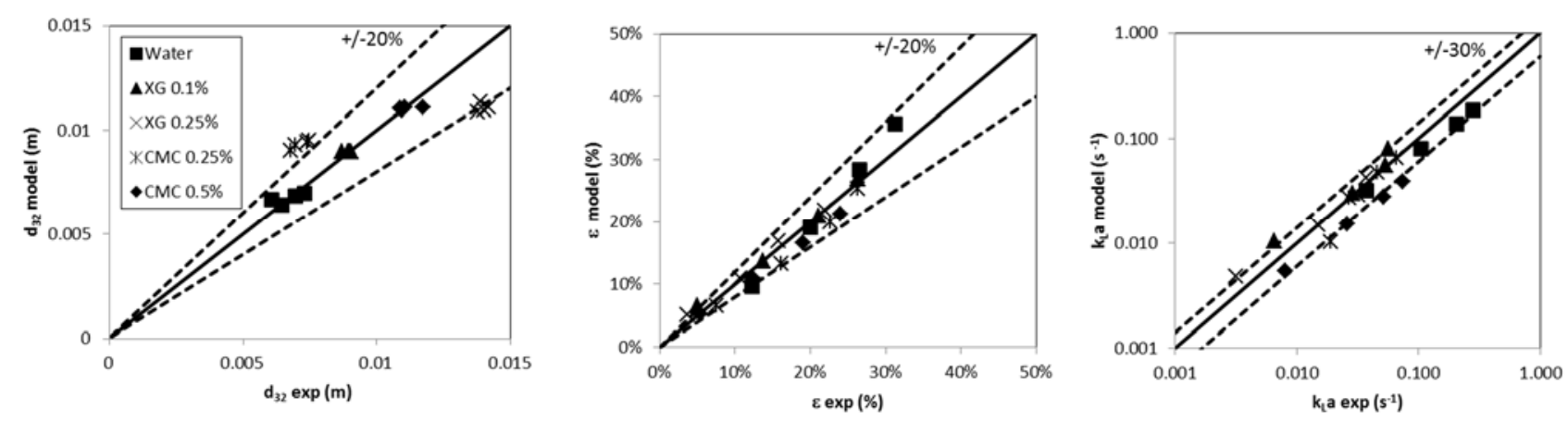

Figure 6 : Parity diagrams of eq. 3 with $A=46 m^{-1}$.

The case of $k_{L}$ is slightly different from the others properties. A model of $k_{L}$ following the expression reported in eq. 3 has been proposed in a previous work ${ }^{[11]}$ concerning aerated stirred tanks with nonNewtonian fluids. The developed model use the following parameters : $a=1.01 e-4, b=0$ (no effect of $\mathrm{V}_{\mathrm{sg}}$ ), $\mathrm{c}=-0.25$. But the shear rate was linked to the stirring rate via the Metzner-Otto approach, and not to the superficial gas velocity. When the latter model of $k_{L}$ is applied to present results with $A=46$ $\mathrm{m}^{-1}$ or $2800 \mathrm{~m}^{-1}$ (see figure 7 ), the resulting correlation predict all experiments with an acceptable accuracy, excepted the case of water that is observed as more impacted by the $\mathrm{V}_{\mathrm{sg}}$ than the other fluids. A similar standard deviation of $37 \%$ approximately is obtained for both values of $A$, but excluding the water experiments from the calculation.

Nonetheless, even for water the range of magnitude of measured $\mathrm{K}_{\mathrm{L}}$ is well predicted by the model. The proposed model of $k_{L}$ appears thus as well adapted to two very different investigated flows, stirred $^{[11]}$ or not (present study), at low to high gas fraction, and adapted to fluids of various rheologies, excepted very low viscous fluids that are apparently more affected by turbulence. 
Finally, looking at experimental results and parameter values of the table 3 can lead to following remarks:

- Differences of $d_{32}$ between investigated fluids are mainly governed by the rheology and not $\mathrm{V}_{\mathrm{sg}}$.

- Similarly, the rheology of the tested fluids explains by itself the differences of $k_{\llcorner}$measured, except for water where the $V_{s g}$ has a strong effect.

- $\varepsilon$ and $\mathrm{k}_{\mathrm{L}} \mathrm{a}$ are governed by both $\mathrm{V}_{\mathrm{sg}}$ and rheology, all other affecting properties being constant or supposed to be.
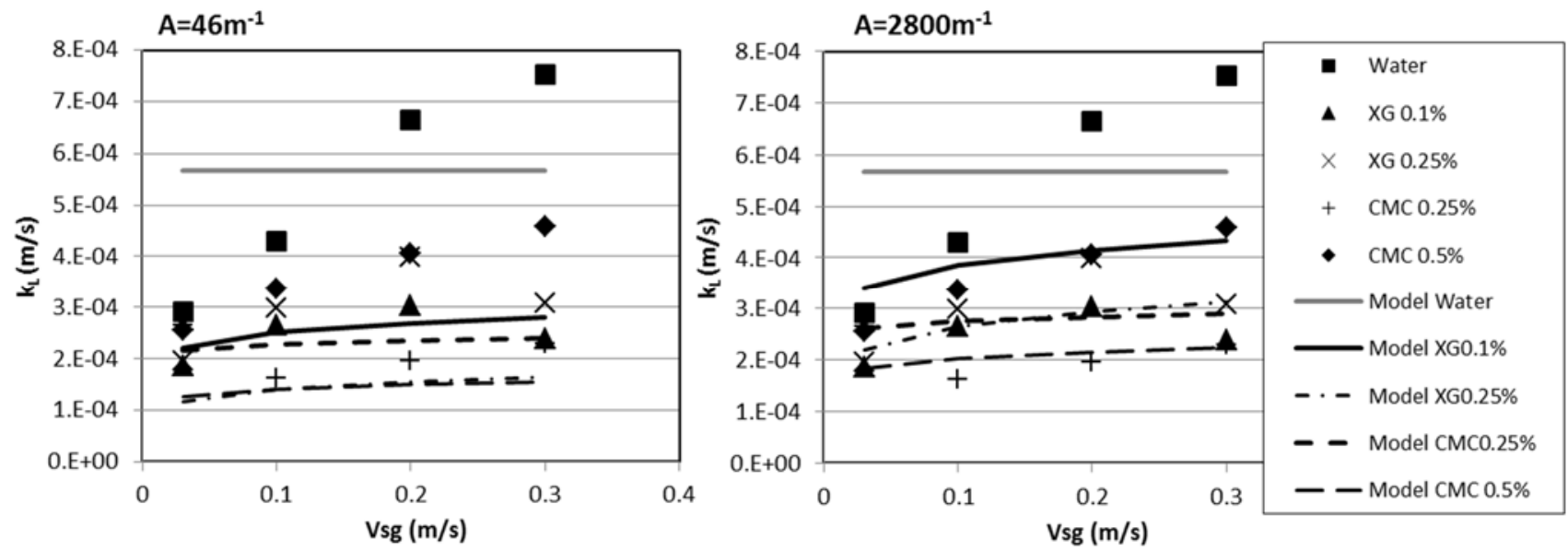

Figure 7 : Experimental estimations of $k_{L}$ and comparison with the model of Cappello ${ }^{[11]}$ in table 3 ( cases $A=46$ and $2800 m^{-1}$ ).

\section{Conclusions}

The new «Cross-Correlation » method has been used for the first time in order to measure Sauter mean bubble sizes in a bubble column operated at high superficial gas velocity, and in presence of non-Newtonian (shear-thinning) fluids. These original results consist in a very useful databank for future physical modeling and validation, particularly in the field of Population Balance modelling. In 
the present work, results have been completed by measurements of gas holdup and mass transfer coefficients. As a consequence, the liquid side mass transfer coefficient $k_{L}$ has been estimated and compared to an empirical model recently proposed ${ }^{[11]}$ to predict mass transfer in aerated stirred reactors filled with similar non-Newtonian fluids. The acceptable agreement between the $\mathrm{k}_{\mathrm{L}}$ model predictions and the bubble column experiments tend to show the robustness of the model to a wide range of bubbly flows involving non-Newtonian fluids.

Besides, $d_{32}, \varepsilon, k_{L}$ a measurements have been also used to fit a simple set of empirical correlations following the classical expression $a \cdot V_{s g}^{b} \cdot \mu^{c}$. Results showed that the apparent viscosity to use in such correlation can be satisfyingly estimated by the classical expression $\dot{\gamma}=A . V_{s g}$.

\section{Acknowledgements}

Authors would like to thank Vanessa Vincent-Genod, Mickael Mejean and Yanis Nadri for their active contributions to the experimental results. 


\section{References}

[1] F. Garcia-Ochoa, E. Gomez. Bioreactor scale-up and oxygen transfer rate in microbial processes: An overview. Biotech. Adv. 2009, 27, 153.

[2] A. Schumpe, W.D. Deckwer. Viscous media in tower bioreactors: Hydrodynamic characteristics and mass transfer properties. Bioprocess. Eng. 1987, 2, 79.

[3] J. Xue, M.Al-Dahhan, M.P. Dudukovic, R.F. Mudde. Bubble velocity, size and interfacial area measurements in a bubble column by four-point optical probe. AIChE J. 2008, 54, 2,350.

[4] D.D. McClure, G. Wang, J.M. Cavanagh, D.F. Fletcher, G.W. Barton, Experimental investigation into the impact of sparger design on bubble columns at high superficial velocities. Chem. Eng. Res. Des. 2016, 106, 205.

[5] H. Chaumat, A.M. Billet-Duquenne F. Augier, C. Mathieu, H. Delmas. On the reliability of an optical fibre probe in bubble column under industrial relevant operating conditions. Exp.Therm. Fluid Sci. $2007,31,6,495$.

[6] A. Esmaeili, C. Guy, J.Chaouki. Local Hydrodynamic Parameters of Bubble Column Reactors Operating with Non-Newtonian Liquids: Experiments and Models Development. AIChE J. 2016, 62, 4, 1382.

[7] N. Jamshidi, N. Mostoufi. Investigating bubble dynamics in a bubble column containing shear thinning liquid using a dual-tip probe, Exp. Therm. Fluid Sci. 2018,94, 34.

[8] P. Maximiano Raimundo, A. Cartellier, D. Beneventi, A. Forret, F. Augier. A new technique for insitu measurements of bubble characteristics in bubble columns operated in the heterogeneous regime, Chem. Eng. Sci. 2016, 155, 504.

[9] P. Maximiano Raimundo, A. Cloupet, A. Cartellier, D. Beneventi, F. Augier. Hydrodynamics and scale-up of bubble columns in the heterogeneous regime: Comparison of bubble size, gas holdup and 
liquid velocity measured in 4 bubble columns from $0.15 \mathrm{~m}$ to $3 \mathrm{~m}$ in diameter. Chem. Eng. Sci. 2019, $198,52$.

[10] L. Gemello, C. Plais, F. Augier, A. Cloupet, D.L. Marchisio. Hydrodynamics and bubble size in bubble columns : Effects of contaminants and spargers, Chem. Eng. Sci. 2018, 184, 93.

[11] V. Cappello, C. Plais, C. Vial, F. Augier. Bubble size and liquid-side mass transfer coefficient measurements in aerated stirred tank reactors with non-Newtonian liquids. Chem. Eng. Sci. 2020, 211, https://doi.org/10.1016/i.ces.2019.115280.

[12] L. Gemello, C. Plais C., F. Augier, D.L. Marchisio, Population balance modelling of bubble columns under the heterogeneous flow regime. Chem. Eng. J. 2019, 372, 590.

[13] L. Gemello, V. Cappello, F. Augier, D. Marchisio, C. Plais. CFD-based scale-up of hydrodynamics and mixing in bubble columns, Chem. Eng. Res. Des. 2018, 136, 846.

[14] Z. Liu, X. Li, Z.S. Mao, S. Yuan, C. Yang, Hydrodynamics of gas phase in a shallow bubble column from in-line photography. Chem. Eng. Sci. 2020, doi: https://doi.org/10.1016/i.ces.2020.115703.

[15] G. Besagni, A. Di Pasquali, L. Gallazzini, E. Gottardi, L.P.M. Colombo, F. Inzoli. The effect of aspect ratio in counter-current gas-liquid bubble columns: Experimental results and gas holdup correlations. Int. J. Multiph. Flow. 2017, 94, 53.

[16] S. Sasaki, K. Hayashi, A. Tomiyama. Effects of liquid height on gas holdup in air-water bubble column. Exp. Therm. Fluid Sc. 2016, 72, 67.

[17] J.C. Gabelle, F. Augier, A. Carvalho, R. Rousset, J. Morchain. Effect of Tank Size on kLa and Mixing Time in Aerated Stirred Reactors With Non-Newtonian Fluids. Can.J.Chem.Eng. 2011, 89.

[18] D. Pinelli. The Role of Small Bubbles in Gas-Liquid Mass Transfer in Stirred Vessels and Assessment of a Two-Fraction Model for Noncoalescent or Moderately Viscous Liquids. Chem. Eng. Sci. $2007,62,14,3767$.

[19] D.D. McClure, A.C. Lee, J.M. Kavanagh, D.F. Fletcher, G.W. Barton. Impact of Surfactant Addition on Oxygen Mass Transfer in a Bubble Column. Chem. Eng. \& Techn. 2015, 38(1), 1. 
[20] D.D. McClure, J. Deligny, J.M. Kavanagh, D.F. Fletcher, G.W. Barton. Impact of Surfactant Chemistry on Bubble Column Systems. Chem. Eng. \& Techn. 2014, 37(4), 652.

[21] M. Jamialahmadi, C. Branch, H. Müller-Steinhagen. Terminal bubble rise velocity in liquids. Chem. Eng. Res. \& Des. 1994, 72a(1), 119.

[22] M. Jamialahmadi, H. Müller-Steinhagen. Effect of alcohol, organic acid and potassium chloride concentration on bubble size, bubble rise velocity and gas hold-up in bubble columns. Chem. Eng. J. $1992,50(1), 47$.

[23] M.C. Ruzicka, M.M.Vecer, S.Orvalho, J.Drahoš. Effect of surfactant on homogeneous regime stability in bubble column. Chem. Eng. Sci. 2008, 63(4), 951.

[24] A.D.Anastasiou, N.A.Kazakis, A.A.Mouza, S.V.Paras. Effect of organic surfactant additives on gas holdup in the pseudo-homogeneous regime in bubble columns equipped with fine pore sparger. Chem. Eng. Sci. 2010, 65(22), 5872.

[25] A. Prins, K. van't Riet. Proteins and surface effects in fermentation: foam, antifoam and mass transfer. Trends in Biotechnology. 1987, 5(11), 296-301. 


\begin{tabular}{|c|c|}
\hline Nomenclat & \\
\hline a: & Coefficient of eq. (3) \\
\hline$a\left(m^{-1}\right):$ & Specific interfacial area \\
\hline A: & Coefficient of eq. (3) \\
\hline b: & Coefficient of eq. (3) \\
\hline c: & Coefficient of eq. (3) \\
\hline$d(m):$ & Distance between probes \\
\hline$d_{32}(m):$ & Bubble Sauter mean diameter \\
\hline$D(m):$ & Column diameter \\
\hline$H(m):$ & Height of liquid at measurement location \\
\hline$H_{\llcorner O}(m):$ & Unaerated Liquid Height \\
\hline$K\left(P a . s^{n}\right):$ & Consistency index in a power-law model \\
\hline $\mathrm{k}_{\mathrm{L}}\left(\mathrm{m} \cdot \mathrm{s}^{-1}\right):$ & Liquid side mass transfer coefficient \\
\hline $\mathrm{k}_{\llcorner} \mathrm{a}\left(\mathrm{s}^{-1}\right):$ & Mass transfer coefficient \\
\hline$n(-):$ & Flow index in a power-law model \\
\hline$R_{g}(d)(-):$ & Spatial Cross-correlation \\
\hline$r(m):$ & radial position \\
\hline$R(m):$ & Column radius \\
\hline $\mathrm{V}_{\mathrm{sg}}\left(\mathrm{m} \cdot \mathrm{s}^{-1}\right):$ & Superficial gas velocity \\
\hline$\varepsilon(-):$ & local gas volume fraction (gas holdup) \\
\hline$\dot{\gamma}\left(\mathrm{s}^{-1}\right):$ & Shear rate \\
\hline$\mu($ Pa.s): & Viscosity \\
\hline
\end{tabular}




\section{Table caption}

Table 1 : Water properties

Table 2 : Parameters of the Power law (Herschel-Bulkley) rheological model

Table 3 : Results of the parameter fitting on eq.(3)

\section{Figure caption}

Figure 1: Experimental setup.

Figure 2: Viscosity of fluids at various shear rates.

Figure 3 : Gas holdup radial profiles at $\mathrm{V}_{\mathrm{sg}}=0.03,0.1,0.2$ and $0.3 \mathrm{~m} / \mathrm{s}$.

Figure $4: d_{32}$ radial profiles at $V_{s g}=0.03,0.1,0.2$ and $0.3 \mathrm{~m} / \mathrm{s}$.

Figure 5 : mean Gas holdup, mean $d_{32}$ and kLa measurement versus $V_{s g}$.

Figure 6 : Parity diagrams of eq. 3 with $A=46 \mathrm{~m}^{-1}$.

Figure 7 : Experimental estimations of $k_{\llcorner}$and comparison with the model of Cappello ${ }^{[11]}$ in table 3 (cases $A=46$ and $2800 m-1$ ). 